\title{
ENTRE DENÚNCIAS E DISPUTAS: AS NOTÍCIAS E OS TEXTOS LITERÁRIOS SOBRE/DO AMAPÁ EM JORNAIS OITOCENTISTAS'
}

\author{
BETWEEN COMPLAINTS AND DISPUTES: NEWS AND LITERARY \\ TEXTS ABOUT/FROM AMAPÁ IN NIGHTTH-CENTURY NEWSPAPERS
}

\author{
Valdiney Valente Lobato de Castro
}

\begin{abstract}
RESUMO: Durante a segunda metade do século XIX, a distância geográfica do Amapá, em relação aos principais centros urbanos, produzia uma imagem de terra remota, inóspita e exótica, que se propagou por muitos anos. No entanto, essa história da região pode ser recomposta por meio dos jornais brasileiros oitocentistas, capazes de auxiliar a desvendar a compreensão acerca da história da região e das produções literárias escritas sobre ou nas terras amapaenses, que, à época, pertenciam ao Grão-Pará. Repousa nesse intuito o objetivo deste artigo: analisar, a partir de publicações, principalmente literárias, saídas nos jornais oitocentistas, como se desenhou, de 1850 a 1900, a imagem do Amapá. Para tanto, foram coligidas publicações de textos literários e notas relativas ao desenvolvimento da população, as quais podem ajudar também a compor um cenário sobre a circulação da literatura. Assim, a partir da pesquisa, será possível relacionar a evolução da identidade da sociedade com as produções literárias saídas nos jornais, bem como ampliar o entendimento sobre a relação que o Amapá, no Oitocentos, mantinha com os demais estados do país por meio da circulação dos impressos.
\end{abstract}

PALAVRAS-CHAVE: Literatura. Jornal. Oitocentos. Amapá.

ABSTRACT: During the second half of the 19th century, the geographic distance of Amapá, in relation to the main urban centers, produced an image of a remote, inhospitable and exotic land, which spread for many years. However, this history of the region can be reconstructed through nineteenth-century Brazilian newspapers, able to help unravel the understanding of the history of the region and the literary productions written on or in the lands of Amapá, which, at the time, belonged to Grão-Pará. The objective of this article rests on this aim: to analyze, from publications, mainly literary, published in nineteenth-century newspapers, how the image of Amapá was drawn, from 1850 to 1900 . For this purpose, publications of literary texts and notes on the development of the population were collected, which can also help to compose a scenario about the circulation of literature. Thus, from the research, it will be possible to relate the evolution of society's identity with the literary productions published in newspapers, as well as broaden the understanding of the relationship that Amapá, in the 1800 s, had with the other states of the country through circulation of prints.

KEYWORDS: Literature. Newspaper. Eight hundred. Amapá.

\footnotetext{
${ }^{1}$ Artigo recebido em 30 de agosto de 2021 e aceito para publicação em 15 de outubro de 2021

${ }^{2}$ Valdiney Valente Lobato de Castro é professor titular da Faculdade Estácio do Amapá, possui doutorado em Letras pela Universidade Federal do Pará, bolsista do Programa Pesquisa Produtividade da Faculdade Estácio do Amapá, faz pós doutoramento na Universidade Federal do Amapá. E-mail: valdineyvalente@hotmail.com. ORCID: https://orcid.org/0000-0002-6704-9218.
} 


\section{As décadas de 1850 e 1860 e as notícias sobre 0 povoamento do Amapá}

Desde meados do século XVIII, graças aos esforços de Mendonça Furtado, governador do Grão-Pará, o processo de povoamento das terras macapaenses já havia sido implantado com a criação da vila de Macapá em 1758, atendendo ao plano imperialista de proteger a Amazônia. No entanto, a vida dos primeiros colonos era repleta de dificuldades: as plantações eram comumente destruídas com as chuvas, e as febres assolavam os moradores que, sem assistência, não resistiam. Esses dissabores, além de gerar um custo alto para o império por arcar com a alimentação dos agricultores, ocasionava com que muitos deles abandonassem as terras, o que não permitiu um aumento significativo da população.

Com a independência política do Brasil, no início do século XIX, os próprios brasileiros passaram a assumir os cargos antes ocupados pelos portugueses e novos incentivos como terra, casa e dinheiro são oferecidos para as famílias que se fixassem no Amapá, atraindo diversos moradores como os cabanos anistiados. Há, de fato, um avanço com o surgimento de engenhos e fazendas de gado que contribui para que Macapá, em 1856, seja elevada à condição de cidade. Desse modo, na metade do XIX, é possível perceber a situação de desenvolvimento da população:

Em 1862, o panorama transformara-se indicando progresso. Em Macapá, contavam-se 2.780 habitantes, dos quais 2.058 eram livres e 722 escravos; em Mazagão, 3.653 habitantes, sendo 329 escravos e 3.324 livres. Os estabelecimentos industriais somaram 471, em Macapá, com 1.409 braços. Os engenhos elevaram-se a 8, movidos por animais. Havia 2 curtumes, 60 pequenas fábricas de sabão, 1 olaria e 400 sítios de fazer farinha. As fazendas de gado eram em número de 82 , com rebanho de 22.000 cabeças, e as propriedades agrárias, de 40 . Plantava-se cacau, feijão, miIho, arroz, café, algodão, fumo e urucu. A borracha já constituía, porém, o forte da ocupação dos munícipes: 10.000 arrobas valendo 160:0008000. A farinha representava-se nos 10.000 alqueires; o cacau, nas 400 arrobas, valendo 2:0008000; a castanha, nos 2.500 alqueires, valendo 7:5008000 (REIS, 1949, p. 89). 
Pela descrição, a imagem que se desenha é a de uma região em plena ascensão. No entanto, os jornais da época, longe de se aterem apenas a números, oferecem informações sobre a verdadeira situação da cidade. O jornal paraense $A$ Estrela do Norte, em 07 de janeiro de 1866, relata uma viagem do bispo Dom Antonio de Macedo Costa para Macapá, em novembro de 1865 , e, ao reproduzir as impressões do religioso, relata as "terríveis febres intermitentes", o "sofrível estado de conservação" da igreja e a pouca quantidade de pessoas reunidas na cidade. Nesse mesmo ano, a folha carioca A Pátria, em 17 de janeiro, na seção "Transcrições", passa a divulgar o longo texto "Notas sobre o Amazonas" e, ao tratar de Macapá, especialmente em relação à imponência do forte, inclui impressões mais favoráveis do que as do bispo: "Macapá não é um sítio doentio, "há abundância de gado e de viveres", "reina em Macapá uma viração constante que refresca a atmosfera".

Jornais de diferentes locais do país divulgavam as notícias sobre a região, muitas vezes transcritas de gazetas paraenses que, graças à proximidade da terra e às viagens regulares para o Amapá, publicavam constantemente informações sobre os mais diferentes assuntos: transportes de couro e borracha, nomeações de cargos públicos, pagamento de salários, gratificações e despesas, partidas dos correios, geralmente nos dias 1 o e 18 de cada mês, requisições de pagamentos de ordenados atrasados, situações dos presos trancafiados na fortaleza de Macapá, remessas de materiais para a construção de obras, decisões dos juízes sobre crimes praticados na região, descrições sobre os negros fugidos a fim de favorecer a captura, relação de pessoas despachadas para a viagem ao Amapá, óbitos ocorridos na região, datas de saídas e chegadas dos paquetes, entre outros.

Nessas notícias, é possível perceber como se deu nas décadas de 1850 e 1860 o processo de implantação e desenvolvimento das escolas, com notas sobre solicitações de pagamentos de ordenados atrasados, despesas com as escolas, lista de materiais enviados para a instrução pública, pagamentos mensais com professores de gramática latina e gramática francesa para as primeiras letras, transferências, nomeações e licenças de professores, e ainda, em 1861, fundação da escola de ensino primário para o sexo feminino. 
Considerando a quantidade da população apresentada na citação de Reis (1949), algumas linhas acima, percebe-se que quase um terço da população da região era formado por negros. Obviamente que essa contagem não absorve os negros fugidos que se abrigavam em diferentes espaços nas terras amapaenses, em virtude da imensidão do território e das dificuldades de penetração das expedições devido às questões geográficas. São exatamente esses personagens, por muito esquecidos, que ilustram grande parte das notícias saídas sobre o Amapá nos jornais de diferentes cidades do país. No entanto, nessas notas, o que salta aos olhos é a barbaridade: nas descrições de escravos fugidos há sempre marcas de maus-tratos; quando o negro é condenado por algum crime, as sentenças são sempre mais severas; nas informações sobre a captura, os negros são punidos com castração ou outros castigos cruéis e, quando morrem, explica-se: "é justificável pelas circunstâncias do momento" (O PUBLICADOR MARANHENSE, 03.05.1851, p. 3).

No Diário do Grão Pará, de 16 de agosto de 1853, foi publicado um ofício do delegado de Macapá, datado de 11 de junho, em que comunica a captura de João, escravo de Feliciano de Souza Gil, fugido há cinco anos. Para evitar ser preso, João havia subido em uma mangueira e, consciente do destino atroz que o aguardava, rasga o ventre e corta em pedaços o intestino para atirá-lo aos soldados que iam na diligência.

Semelhante sacrifício percebe-se no soneto intitulado "Maria Bárbara", composto por Tenreiro Aranha, e divulgado em vários jornais do país. Nessas reproduções, anunciava-se como introdução a seguinte informação: "Mameluca, casada com um soldado do regimento de Macapá (Pará), cruelmente assassinada no caminho da Fonte de Marco por não querer adulterar. $\mathrm{O}$ sr. Tenreiro Aranha achou neste fato objeto para o seguinte soneto" e, em seguida, apresentava-se o poema, transcrito a seguir:

Se acaso aqui topares, caminhante, Meu frio corpo já cadáver feito, Leva piedoso com sentido aspeito Esta nova ao esposo aflito, errante.

Diz-lhe como de ferro penetrante Me viste, por fiel, cravado o peito, Lacerado, insepulto, e já sujeito O tronco feio ao corvo alti-volante; 


\author{
Que d'um monstro inumano, Ihe declara, \\ A mão cruel me trata desta sorte; \\ Porém que alívio busque à dor amara, \\ Lembrando-se que já teve uma consorte. \\ Que, por honra da fé que lhe jurara, \\ À mancha conjugal prefere a morte
}

Como o autor faleceu em 1811 e a publicação do seu livro ocorreu, primeiramente, em 1850, não se sabe quando o soneto começou a ilustrar as páginas dos jornais brasileiros. $\mathrm{Na}$ folha semanal carioca Arquivo Municipal, em 23 de agosto de 1860 , além do poema, foi publicada uma biografia do autor juntamente com informações acerca de sua produção. O poema foi reproduzido também em 1862, no Almanaque Histórico de Lembranças Brasileiras, do Maranhão; em 18 de setembro de 1864, no jornal carioca Brasil Literário; em 1873, no Almanaque Administrativo, Mercantil e Industrial, do Pará; em 15 de novembro de 1883, na folha capixaba Vasco Coutinho; e, ainda, em 1 으 de agosto de 1890 n'O Estado da Paraíba. Em algumas dessas folhas, a história era anunciada como "Lucrécia Paraense" em alusão ao episódio da dama romana, Lucrécia, que se suicida após ter sido estuprada. Curiosamente, Antonio Candido (1959), ao comentar a obra de Tenreiro Aranha, menciona a "situação de Lucrécia" que sofre a infeliz Bárbara.

Além dessa tragédia, o soneto também ilustra uma situação muito comum no início do século XIX: as relações entre as mulheres das colônias e os homens destacados a trabalhar no regimento para a proteção do reino, afeto incentivado à época pelo governador do Grão-Pará, Mendonça Furtado, com a intenção de expansão do povoamento nas terras do Amapá.

Vergolino-Henry e Figueiredo (1990), conscientes dessa importância, caracterizam os diversos papeis que o negro desempenhou no desenvolvimento da nação brasileira, em especial na Amazônia colonial, e observam a inserção do negro na sociedade não apenas como mão de obra para os serviços braçais, mas como esse elemento vai, por mais que muito lentamente e à revelia de muitos, se imiscuindo em pequenos espaços que culminarão com a formação da identidade nacional. 
No soneto, dois aspectos ganham relevância: a presença de uma personagem de vida social de pouca envergadura em uma poesia produzida, provavelmente, entre o final do século XVIII e início do XIX, distante dos tempos de Castro Alves, que só anos depois viria à luz; e a barbaridade que sofre a infeliz esposa do soldado, enleada com o título do soneto. Possivelmente, esses aspectos singulares são a razão de o texto ter circulado por décadas nos jornais do país e em diferentes regiões, o que demonstra o quanto o norte não estava, no Oitocentos, tão distante do que acontecia no país, bem como realça a rede de circulação que permitia com que os impressos percorressem o Brasil de norte a sul.

\section{Os jornais das décadas de 1870 e 1880: descasos, desmandos e denúncias}

Se nas décadas anteriores, as notícias nos jornais abordavam as questões voltadas para o desenvolvimento da cidade, como os transportes de couro e borracha e as nomeações de cargos, a partir de 1870, as notas modificam-se. Parece haver um início de conscientização de sociedade estabelecida, pois, em muitas notícias que circulam sobre o Amapá, há insistentemente indícios da situação complicada da cidade e da chegada de muitos fugitivos. O Liberal do Pará, em 15 de janeiro de 1873, noticia que no dia 25 do mês anterior, dezembro, cerca de trinta escravos pertencentes aos municípios de Vigia e São Caetano evadiram-se em uma canoa e seguiram para o Amapá, "onde tem-se refugiados muitos outros nestes últimos tempos".

A região se desenvolvia com muitos imigrantes dirigindo-se para as terras do contestado, que, devido a um acordo com o governo francês, tornou-se um espaço sem pátria, "um asilo seguro para desertores, escravos fugidos, criminosos e outros. Além das oportunidades ensejadas pelo status de neutralidade política, essas populações tinham à sua disposição vastas terras, abundantes em recursos naturais de significativo valor comercial" (PAZ, 2017, p. 140).

Essa fartura, no entanto, não significa uma situação confortável para os moradores, que sofriam com a criminalidade e a negligência em virtude da ausência de autoridade oficial. Somam-se a essa instabilidade as revoltas ocorridas na tentativa de indepen- 
dência de Cunani, em 1886, e na investida malograda da população em transformar Macapá em uma província, em 1870, para que se perceba a ebulição causada pela insatisfação dos moradores da região diante da situação de abandono em que viviam. 0 jornal carioca Correio Nacional, em 18 de setembro de 1870, na seção "Política", analisa a solicitação assinada por 387 moradores para o surgimento da nova província e pontua que as grandes cidades não podem lutar contra a tirania sufocante da corte e as pequenas não conseguiram ter nem as suas necessidades urgentes atendidas.

Essa crítica ao desmazelo da corte acentua-se nos anos seguintes. Na madrugada do dia 07 de setembro de 1874, quatro portugueses, em seus domicílios, são assaltados e mortos, em Macapá. Essa notícia, que circulou intensamente, a princípio, por meio de telégrafos e, com mais detalhes, pelos jornais, foi divulgada no dia 28 de setembro no jornal carioca $A$ Nação, no dia 10 de outubro na folha também carioca $O$ Apóstolo e no Correio Paulistano. Em todas essas notícias, o direito à vida e à segurança individual é ressaltado. No dia 02 de outubro, o Correio Paulistano reproduz várias notas extraídas d'O Liberal do Pará e destaca a omissão das forças imperiais nas mais distantes regiões do país.

Notícias semelhantes, que demonstraram o quanto a lei no Amapá era aplicada de acordo com as vontades individuais, espalham-se nos jornais. No dia 11 de fevereiro de 1882, sai n'O Liberal do Pará, uma agressiva nota dirigida em defesa de Fernando Álvares da Costa, que vinha sendo atacado anonimamente nas páginas da folha paraense $A$ Constituição. A defesa, assinada por "Um macapaense indignado", acusou que o autor das críticas saídas n'O Liberal é Antonio Marinho, conservador que havia perdido as eleições para os liberais e um "miserável vendilhão" que "passa a perna nos pobres caboclos".

Em 22 de setembro de 1882, nas páginas d'A Constituição (PA), foi publicada uma longa nota sobre a situação de Macapá, dirigida ao presidente da província com o intuito de denunciar a precariedade do serviço público. O texto destaca a falta de habilitação e honestidade das pessoas que ocupam os cargos, o que resulta em privilégios para poucos, abusos de poderes e impunidades. De igual teor, em 28 de junho de 1884, ilustra as folhas do Diário de Belém um texto criticando não apenas os homens da primeira camada social da cidade de Macapá, como também o 
marasmo e o definhamento da civilidade e da instrução: "os maridos abandonam as mulheres, estas os maridos, a prostituição em larga escala, enfim, o despotismo, a intriga, o servilismo chegaram no seu maior auge". Também em 22 de outubro de 1886, A Constituição (PA) apresenta uma crítica ao juiz de direito de Macapá, acusando-o de "saltar sobre as leis" para defender o seu partido.

A situação de abandono e descontrole que a cidade vivia estende-se para as questões voltadas para o ensino. Nos dias 25 de abril e 14 de junho de 1871, foi publicada, n'O Liberal do Pará, uma carta assinada por "três amigos da instrução", dirigida ao redator da folha em que denuncia o professor Manoel Pinho, que aluga, por valores exorbitantes, sua própria casa em péssimas condições para ministrar suas aulas, expondo os alunos ao risco de desabamento. Além disso, a matéria ainda acusa o professor de abusos em relação à indisposição com os pais de família e de aulas em horários aleatórios, sem fixar hora regular de entradas e saídas. Em 25 de novembro de 1880, sai n'A Constituição (PA) uma crítica assinada por "um pai de família" sobre a situação da casa onde funciona a escola, que é "uma miséria", e do professor, "que é incapaz para o cargo que exerce a ponto de dizer ele mesmo que não ensina o sistema métrico decimal por não sabê-lo".

Mesmo com as denúncias quanto aos descasos com a situação das escolas, as notas permitem perceber como se desenvolvia paulatinamente o ensino em Macapá. Em 26 de junho de 1872, O Liberal do Pará divulgou que havia sido criada pela câmara municipal uma escola noturna para adultos com 55 alunos matriculados e frequentando. Na mesma folha, em 28 de agosto de 1879, publica-se um quadro estatístico das matrículas e frequências das escolas públicas da província distribuídas por comarca e, em Macapá, constam 5 escolas com 158 matrículas e 121 frequências, a menor quantidade de todas as comarcas citadas no quadro.

No dia 16 de julho de 1885, nas folhas Diário de Notícias e $O$ Liberal do Pará, anuncia-se que Cora Clotilde de Carvalho foi nomeada para reger a cadeira de $2 \underline{a}$ entrância em Macapá. Esse papel da figura feminina vinculado à educação é ilustrado no discurso proferido pela professora Idalina Augusta de Novais Farias, realizado em 2 de fevereiro de 1884 e divulgado n'A Constituição (PA) no dia 23 do mesmo mês. A explanação ocorre por ocasião de um chá oferecido por Antonio Claro de Farias, esposo da 
professora, aos capitães Alfredo de Amorim Caldas e Alfredo da Costa Weyne. No texto, eivado de uma linguagem bem cuidada e metafórica, com expressões como "sou como a flor em débil haste, precisa do rocio da manhã para seu completo viço", a anfitriã acentua a necessidade de amor à pátria, a importância da família para a instrução das crianças e a tarefa da professora na difusão da instrução e da manutenção da moralidade, pois ela "deve ser o modelo dos bons costumes sociais; convém que seja a mais moralista possível, para assim chegar ao bom desempenho de sua árdua missão e para captar a simpatia e a estima desse círculo". É bem verdade que o tom elogioso aos convidados e a preocupação com a decência e com os princípios da moral são excessivos no discurso, mas é preciso analisar a preocupação com a instrução pública e, para além do texto, a atitude corajosa da mulher que, em meio a uma sociedade patriarcal e provinciana e diante de uma plateia formada por pessoas do mais alto escalão, professa seus pensamentos acerca do ensino.

Com todos os desmandos e denúncias que proliferavam abundantemente nas folhas públicas, a literatura, inevitavelmente, seria impactada. Quando Candido (2011, p. 34) aborda o quanto as forças sociais condicionam a produção da obra, ele lembra que muitas vezes a composição do autor é resultado das aspirações e valores do seu tempo, promovendo uma relação dialética entre o homem e o grupo do qual faz parte:

\footnotetext{
Os elementos individuais adquirem significado social na medida em que as pessoas correspondem a necessidades coletivas; e estas, agindo, permitem por sua vez que os indivíduos possam exprimir-se, encontrando repercussão no grupo às aspirações e valores do seu tempo, que parece dissolver-se nele, sobretudo levando em conta que, nestes casos, perde-se quase sempre a identidade do criador-protótipo (CANDIDO, 2011, p. 34).
}

Nos dias 26 e 27 de fevereiro de 1887, foram publicadas no Diário de Notícias, poesias assinadas com pseudônimos, Neve e Sesipho, respectivamente, as quais caracterizam com exatidão essa necessidade do indivíduo em compor obras que reproduzam a necessidade de seu grupo social, como um impulso surgido a partir dos valores sociais: as denúncias do que ocorria em Macapá: 
É horroroso, meu Deus, ver-se o estado

A que está reduzido Macapá!

Está pior que o governo do Amapá

Por ser Mucio um juiz mui depravado.

Dos contrários a pena do malvado

Não trepida em escrever mentiras vis;

Por serem homens sinceros e não servis

Que hão de reagir co'esse danado (...)

(Diário de Notícias, 26 fev. 1887, p. 3)

Avante, triste capacho

Juiz de meia tigela

Persegue aos conservadores

Bota fogo na panela.

Mucio anda atarantado

Faz ofício, não assina

Foi-lhe logo devolvido

Oh! Que sorte, que má sina! (...)

Chega Mucio a Macapá,

Ficou muito admirado,

Por ver um triste coqueiro

Carcomido e escangalhado;

Ele tinha três cabeças

Múcio então fez-se poeta

Sonetou esse coqueiro...

Oh! Que tolo! Que pateta!...(...)

(Diário de Notícias, 27 fev. 1887, p. 3).

Nos dois textos satíricos, a crítica foi direcionada a Mucio de Rialva ${ }^{3}$ que, no ano de 1887, esteve brevemente em Macapá como juiz de direito. Nos dois quartetos extraídos do soneto saído no dia 26, a adjetivação dirigida ao personagem é sempre negativa e, na poesia do dia 27, a qualificação não é menos pejorativa. Ao contrário. Não o acusa apenas como péssimo magistrado, mas inferioriza também seu ofício de poeta. Apesar de ter participação curta em Macapá, como a própria poesia revela ao afirmar que foi devolvido, Mucio, no ano anterior, em 1886, na Bahia, mandou seu livro de poesias para o Diário de Notícias, em Belém.

\footnotetext{
${ }^{3}$ Pouco se sabe sobre essa personalidade. As poucas notações sobre ele referem-se à composição de um pequeno livro de poesias intitulado Ephemérides, escrito na Bahia e divulgado o recebimento no escritório da folha paraense Diário de Notícias, em 28 de maio de 1886. Já em 14 de dezembro de 1890, a poesia "Piano-piano", escrita por ele, ilustra as páginas do jornal paraense $A$ República. Além dessas informações, não há nenhuma outra nos livros de História do Amapá ou nos documentos da época, possivelmente, pelo breve tempo em que esteve no cargo.
} 
Nas décadas de 1870 e 1880, as viagens dos vapores tornam-se mais regulares, estreitando as relações entre os moradores das comarcas e dinamizando as notícias. No dia 02 de março de 1884, por exemplo, Raimundo Justiniano Pereira escreve um texto para o jornal $A$ Constituição, lamentando a morte do amigo Albino Furtado de Vasconcelos Leão, morador da comunidade de Itanduba, na comarca de Cametá. No texto, saído na folha paraense no dia 07 de março, o saudoso emissor envia as condolências à família, deseja à alma do amigo o repouso eterno e informa que soube do triste padecimento por meio dos jornais. A pesarosa nota além de destacar a agilidade dos impressos: em cinco dias o texto escrito em Macapá já está impresso e circulando nas ruas de Belém, o que destaca a comunicação entre as terras do Grão-Pará.

\section{As notícias de 1890: entre as lutas de independência e 0 afă nacionalista}

No final da década de 1880 , as disputas no solo amapaense pela demarcação da terra se intensificaram motivadas pela descoberta do ouro, na região do Cunani, que gerou a tentativa de independência, e em Calçoene, resultando na corrida de ouro e no conflito armado com os franceses, em 1895. Desse modo, o confronto com a França, que há anos se postergava, eclode e, com a necessidade urgente de demarcar o território e pôr fim aos conflitos com os países vizinhos, devido à Proclamação da República em 1889, torna-se imperioso solucionar a pendência com o governo francês.

Seguramente é nesse momento que o Amapá ganha mais destaque, tornando-se notícia em jornais de todo o Brasil: de norte a sul do país, detalha-se sobre a questão do Amapá, desde 1897, quando se esclarece que o tribunal onde será decidida a contenda entre os dois países será na Suíça, até 1900, quando os argumentos de Barão do Rio Branco conduzem à decisão vitoriosa do Brasil. Apesar da conquista, a situação da população não era confortável. Se as lutas pela posse da terra se intensificaram com a descoberta do ouro, a década de 1890, para os amapaenses, não foi marcada pela riqueza com a apropriação desse minério. 0 Diário de Notícias, do Pará, em 08 de fevereiro de 1891, no início da década, já divulgava que a fome, a peste e a miséria assolavam Macapá, arrastando muitas pessoas à sepultura. 
Em 1899, próximo a ser resolvido o atrito com a França, uma epidemia de varíola também vitimou muitos moradores. $\mathrm{O}$ jornal $O$ Pará, em 18 de setembro, divulgou a doença e no dia 20 do mesmo mês, o paraense $A$ República alertou que a varíola estava "dizimando a população, paralisando os trabalhos, sem que até hoje se tivesse tomado a mínima providência" e acrescentou que "a população aterrorizada, busca outros lugares; afinal, paralisam-se todos os negócios, e se não se tomar providências enérgicas para a exterminação do terrível morbus, daqui há poucos dias o Amapá estará despovoado completamente".

A situação estava tão pesarosa que uma viagem a Macapá era considerada uma sentença de morte. Em 22 de abril de 1893, o coronel Carlos Soares foi punido por Floriano Peixoto a ir para o Pará com o intuito de esboçar a planta do forte de Macapá, mas com intenções "sinistras e ferozes", já que "Macapá é uma decadente povoação considerada como a ante comarca da morte", como divulgou o carioca Gazeta da Tarde, em 19 de janeiro de 1895. O Pará, em 17 de junho de 1899, noticiou que dois deputados, Cassiano do Nascimento e Lauro Muller, ao saberem que precisarão ir a Macapá, choram com "medo e pavor da morte".

Além da miséria e da doença, os abusos de poder e os desmandos ainda proliferavam: em 04 de julho de 1896, o Diário de Notícias, do Pará, publicou que o juiz de Macapá não atendeu o pedido de Honória Joaquina Pereira, violentada pela usurpação de suas próprias terras; enquanto João Francelino, que havia amarrado uma menor de 9 anos para "satisfação de seus instintos deixando-a em um estado lastimável", foi protegido e nada lhe aconteceu. Essa indiferença com o direito da mulher ocorre também com Mergelina Borges, que, em 25 de fevereiro de 1894, também no Diário de Notícias, tem publicado seu protesto contra o marido, o coronel José Antonio da Costa, comandante superior da guarda nacional. No texto, a esposa, abandonada pelo marido, acusa o ilustre comandante de negociatas ilícitas e de, ao ter se amasiado, vender propriedades sem lhe deixar nenhuma garantia. No ano seguinte, em 07 de fevereiro, no mesmo jornal, foi noticiada a chegada de Mergelina a Belém com os seguintes adjetivos: "cadavérica, maltrapilha e com a fronte curvada sob o peso de tantos infortúnios", certamente por não ter o seu direito resguardado, em virtude do cargo ocupado pelo seu ex-esposo, "honesto e conspícuo cidadão". 
Sendo a década de 1890 marcada por tantas atribulações e a imagem de Macapá cada vez mais arruinada nos jornais, era natural que as composições literárias representassem esses dissabores e, por isso, em 04 de outubro de 1890, O Democrata (PA) apresenta uma poesia improvisada de Gonçalo de Lima, que cita o "infecto Amapá", e, no dia 16 de outubro de 1890, A República (PA), divulga a "Canção do Vagabundo", que menciona "o inferno do Amapá". Quando, em 1895, houve a invasão dos franceses, que resultou na morte de muitos brasileiros, dois jornais cariocas, $O$ País e Gazeta da Tarde, em 14 de março de 1896, publicam a trova assinada por Gavroche: "Diz o povo: O anzol não morde, / Vê lá, governo, vê lá! / Anda tudo em desacordo / Com o acordo do Amapá".

Certamente, nenhuma dessas representações produz uma imagem favorável sobre a região, problema que se intensifica ao se considerar que esses jornais circulavam em diversos estados do país. No entanto, há composições que apresentam não só mais sensibilidade com os dilemas da região, como também se solidarizam com a tragédia. Em 10 de março de 1896, no jornal paraense Folha do Norte, foi publicado o soneto "Amapá", assinado pelo pseudônimo "Faneca", também com realçados tons nacionalistas.

\author{
Tanta fraqueza, tanta, uma guarida \\ Crer eu não devo achasse em peito humano \\ Qu'inda rutila com imensa vida \\ Em nossa mente um nome - Floriano! \\ Da França a atroz protérvia, Brasileiro, \\ Devemos rechaçar sem compaixão! \\ Da pátria a integridade ao mundo inteiro, \\ Dever nosso é mostrar não ser ficção! \\ Heróis do Paraguai! Mostremos, ela, \\ Unidos todos pela mesma ideia, \\ Que o franco a Pátria não aviltará! \\ Que essa extorsão o ardor nos estimule \\ Contra o inimigo e, impávido, tremule \\ Sempre o pendão brasílio no Amapá
}

A poesia é marcada por estruturas sintáticas invertidas, indignação contra a petulância da França e invocação da força brasileira para destroçar os inimigos franceses. Esse teor nacionalista é 
a marca das produções brasileiras da década, não só por dialogarem com a proposta republicana, como também por ser uma reação aos muitos anos de abandonos e abusos que a região sofreu. Assim, os conflitos com os franceses buscaram garantir a posse da terra brasileira, legitimada a partir da intercessão do Barão do Rio Branco e da vitória com o laudo suíço, o que foi ovacionado nas páginas impressas de todo o país. No entanto, na região, os confrontos acirraram a representação de um espaço apartado do resto do país onde proliferava a morte, a miséria e a violência, imagem que a literatura, ainda que de modo comedido pelas poucas publicações, tentou transformar em símbolo de resistência na defesa pelo território nacional.

\section{Consideraçôes finais}

Na segunda metade do século XIX, a região do Amapá foi aos poucos se desenvolvendo, marcada pela chegada de imigrantes que se aproveitavam da ausência de leis no contestado para se refugiarem e/ou explorarem o ouro; ou iam ao Amapá assumir cargos nomeados pelo governo do Grão-Pará; ou, ainda, eram atraídos pelos benefícios oferecidos para o povoamento da região. Mesmo com todas essas seduções, o aumento no número de habitantes não crescia tão favoravelmente quanto o governo esperava: as epidemias com um número expressivo de mortos, os conflitos constantes pela terra e o descaso com os moradores desenhavam um cenário assustador que coibia quaisquer esforços de progresso. Todos esses malefícios se intensificavam com os desmandos que, favorecidos pela distância com o governo paraense, grassavam impiedosamente afligindo a população.

É preciso pensar como foi se estabelecendo essa sociedade, composta por diversas forças (política, econômica e cultural) que ao competirem e, ao mesmo tempo, conflituarem entre si, refletiam nas articulações entre as classes e ajudavam a constituir a identidade da região, porque as relações sociais estão intimamente imbricadas com as práticas culturais. Nesse sentido, os jornais surgem como um suporte fundamental, pois por meio dele é possível recuperar os acontecimentos divulgados periodicamente, o comportamento da sociedade 
diante desses eventos, e as múltiplas concepções compartilhadas pelas pessoas envolvidas no processo de produção, circulação e recepção dessas notícias.

Essa investigação permite com que se perceba como os traços culturais são reconstituídos de acordo com uma intenção discursiva caracterizada por aspectos ideológicos, publicados nos jornais e reproduzidos em diversas partes do país, como ocorre com o massacre praticado pelos franceses, que gera textos tanto indignados com o trágico acontecimento quanto desqualificando a região, marcada pelos conflitos. Assim, não há neutralidade nesses textos; são construções que atendem aos interesses daqueles que escrevem. É bem verdade que, a partir do momento em que o texto circula em cadeia, como na teia urdida de circulação dos impressos no Oitocentos brasileiro, ele passa a se legitimar como uma concepção coletiva, graças à projeção nacional. São esses textos repletos, muitas vezes, de imagens diminutas, fragmentadas, ou até mesmo equivocadas que passam a compor o imaginário nacional acerca da realidade da população amapaense oitocentista.

No entanto, a pesquisa atenta nas notícias dos jornais e a constatação dos desmandos e denúncias leva à revisão das construções produzidas pelas hierarquias sociais e políticas e à condução das descobertas do que foi silenciado/apagado acerca do passado cultural, o que se coaduna com a compreensão de Bauman (2005) acerca das vozes sociais presentes nos textos, tanto as que estão explícitas quanto as que estão silenciadas, que oferecem base para o leitor questionar a identidade e compreender que a alteridade é necessária para ele se situar no tempo em que o texto foi produzido e recebido pelos leitores. A esse arguto leitor, oitocentista ou não, cabe a possibilidade de aceitar, como os que, ao invés de criticarem o massacre, menosprezaram o estado construindo uma imagem de pavor para os leitores, ou de reagir, questionamento a barbárie da tragédia, como os versos nacionalistas.

Em meio a essas notícias carregadas de desvelamentos às injustiças sociais, como as perseguições e torturas aos negros escravizados e as que retratam os abusos de poder, saltam aos olhos as que se referem às mulheres. Três publicações, em décadas diferentes: a poesia sobre o malfadado destino de Bárbara, o discurso proferido pela professora Idalina Augusta de Novais Farias e a notícia com o triste padecimento de Mergelina Borges caracterizam 
reações, dentro do limite possível, às imposições sociais de uma sociedade patriarcal e provinciana: a esposa que prefere morrer do que se entregar à libido do agressor, a ex-esposa que protesta nos jornais contra a desonestidade do marido e até mesmo a professora que discursa em prol do ensino para uma plateia predominantemente masculina. São atitudes que se opõem à condição da mulher na segunda metade do século XIX, porque, além de apresentar uma densidade estrutural na articulação da sociedade com um significado concreto, são convictas de suas vontades, as quais penetram na hermética urdidura da cadeia social da época.

Além de questões sociais e identitárias, essas notícias revelam o poder de penetração e circulação dos impressos. As viagens constantes dos navios permitiam com que os jornais chegassem regularmente às cidades de Macapá e Mazagão, possibilitando com que as notícias ocorridas nas terras amapaenses rapidamente alcançassem as folhas públicas, como ocorre com a notícia do falecimento do amigo de Raimundo Justiniano Pereira, em 1884 que, em cinco dias após ser escrito em Macapá, já está publicado nas páginas d'A Constituição. Esse ritmo dos impressos é ainda mais frenético, ao se considerar que essas notícias circulavam em jornais de diferentes partes do país, o que revela o quanto as terras amapaenses não eram tão apartadas do resto da nação brasileira como costumeiramente se acredita.

Todos esses aspectos permitem compreender os jornais como o principal meio de leitura da sociedade oitocentista, responsáveis não apenas por divulgar as notícias como também por promover a interligação dos diferentes espaços do país. Mesmo nas regiões de difícil acesso, as folhas públicas penetravam levando os registros diários acerca dos principais acontecimentos das províncias e possibilitando que as produções literárias e os autores, nacionais ou não, fossem conhecidos por todo o Brasil oitocentista.

\section{Referências}

A Estrela do Norte, Belém (PA): edição de 1866.

A Nação, Rio de Janeiro (RJ): edição de 1874.

A Pátria, Rio de Janeiro (RJ): edição de 1866. 
A República, Belém (PA): edições de 1890 e 1899.

Almanaque Administrativo, Mercantil e Industrial, Belém (PA): edição de 1873.

Almanaque Histórico de Lembranças Brasileiras, São Luís do Maranhão (MA): edição de 1862.

Arquivo Municipal, Rio de Janeiro (RJ): edição de 1860.

A Constituição, Belém (PA): edições de 1880, 1882, 1884, 1886.

ASSIS, M. d. Quincas Borba. Disponível em: http://www.dominiopublico.gov. br/download/texto/bn000106.pdf. Acesso em 15 de março de 2021.

BAUMAN, Z. Identidade. Entrevista a Benedetto Vecchi. Tradução de Carlos A. Medeiros. Rio de Janeiro: Jorge Zahar, 2005.

BOURDIEU, P. As Regras da Arte: Gênese e Estrutura do Campo Literário. 1. ed. Trad. Maria Lúcia Machado. São Paulo: Companhia das Letras, 1992.

Brasil Literário, Rio de Janeiro (RJ): edição de 1864.

CANDIDO, A. Formação da Literatura Brasileira. São Paulo: Livraria Martins Editora, 1959.

CANDIDO, A (1988). O direito à literatura. In: Vários escritos. 5. ed. Rio de Janeiro: Ouro sobre Azul, 2011, p. 171-193.

Correio Nacional, Rio de Janeiro (RJ): edição de 1870.

Correio Paulistano, São Paulo (SP): edição de 1874.

Diário de Belém, Belém (PA): edição de 1884

Diário de Notícias, Belém (PA): edições de 1885 a 1887, 1891, 1896.

Diário do Grão-Pará, Belém (PA): edição de 1853.

Folha do Norte, Belém (PA): edição de 1896.

Gazeta da Tarde, Rio de Janeiro (RJ): edições de 1895 e 1896.

GREGÓRIO, V. M. Uma face de Jano: a navegação do rio Amazonas e a formação do Estado brasileiro. 2008. 339 f. Dissertação (Mestrado) - Universidade de São Paulo (USP), Faculdade de Filosofia, Letras e Ciências Humanas, 2008.

Jornal do Recife, Recife (PE): edição de 1895.

O Apóstolo, Rio de Janeiro (RJ): edição de 1874. 
O Democrata, Belém (PA): edição de 1890.

O Estado da Paraíba, João Pessoa (PB): edição de 1890.

O Liberal do Pará, Belém (PA): edições de 1871 a 1874, 1879, 1882 a 1885.

O País, Rio de Janeiro (RJ): edição de 1896.

O Pará, Belém (PA): edição de 1899.

O Publicador Maranhense, São Luís do Maranhão (MA): edições de 1851 e 1866.

O Republico, Rio de Janeiro (RJ): edição de 1853.

Pacotilha, São Luís do Maranhão (MA): edição de 1895.

PAZ, A. J. F. Repúblicas contestadas: liberdade, trabalho e disputas políticas na Amazônia do século XIX. 2017. 296 f. Tese (Doutorado) - Universidade Estadual de Campinas, Instituto de Filosofia e Ciências Humanas, 2017.

PAZ, A. A voz do extremo Norte: crise, trabalho e desenvolvimento nas páginas do jornal Pinsonia (1895-1897). In: César Augusto Bubolz Queirós e Gláucia de Almeida.

Campos (orgs.). Trabalho e trabalhadores na Amazônia: caminhos e possibilidades para uma história em construção. Manaus: EDUA, 2017.

PINA, P. K. d. C. Literatura e Jornalismo no oitocentos brasileiro. Ilhéus: EDITUS, 2008.

REIS, A. C. F. Território do Amapá: perfil histórico. Rio de Janeiro: Departamento de Imprensa Nacional, 1949.

SARNEY, J.; COSTA, P. Amapá: a terra onde o Brasil começa. 2.ed. Brasília: Senado Federal, 1999.

Vasco Coutinho, Vitória (ES): edição de 1883.

VERGOLINO-HENRY, A.; FIGUEIREDO, A. N. A Presença Africana na Amazônia Colonial: Uma notícia histórica. Belém, Arquivo Público do Pará, 1990. 